\title{
Fault Diagnosis of Car Engine by Using a Novel GA-Based Extension Recognition Method
}

\author{
Meng-Hui Wang ${ }^{1}$ and $\mathrm{Pi}-\mathrm{Chu} \mathrm{Wu}^{2}$ \\ ${ }^{1}$ Department of Electrical Engineering, National Chin-Yi University of Technology, 411 No. 35, Lane 215, Sec.1, \\ Chung-Shan Road, Taichung County, Taiwan \\ ${ }^{2}$ Department of Marketing and Logistics, China University of Technology, 116 No. 56, Sec. 3, Xinglong Road, \\ Wenshan District, Taipei City, Taiwan \\ Correspondence should be addressed to Meng-Hui Wang; wangmh@ncut.edu.tw
}

Received 16 December 2013; Accepted 15 February 2014; Published 17 March 2014

Academic Editor: Her-Terng Yau

Copyright (C) 2014 M.-H. Wang and P.-C. Wu. This is an open access article distributed under the Creative Commons Attribution License, which permits unrestricted use, distribution, and reproduction in any medium, provided the original work is properly cited.

\begin{abstract}
Due to the passenger's security, the recognized hidden faults in car engines are the most important work for a maintenance engineer, so they can regulate the engines to be safe and improve the reliability of automobile systems. In this paper, we will present a novel fault recognition method based on the genetic algorithm (GA) and the extension theory and also apply this method to the fault recognition of a practical car engine. The proposed recognition method has been tested on the Nissan Cefiro 2.0 engine and has also been compared to other traditional classification methods. Experimental results are of great effect regarding the hidden fault recognition of car engines, and the proposed method can also be applied to other industrial apparatus.
\end{abstract}

\section{Introduction}

Cars are an important tool in human life, and as such the traffic accidents have become a part of human life as well. There are many kinds of traffic accidents with various causes. Sometimes the drivers cause the accidents, and sometimes they are caused by engine faults. An engine fault not only damages the engine itself but can also break the car system. Usually, the component module of the engine generates a natural loss and improper maintenance that will cause a gradual increase of engine oil consumption and lead to an increase in exhaust thickness. The cylinder vibration and the temperature of engine exhaust will become abnormal. This type of the hidden defect is gradually formed, so it is difficult to recognize in the normal inspection. Therefore, it is necessary to know how to recognize the signs of engine faults early and to immediately repair or remove them. The evaluation of safety management has become a crucial issue for enterprises.

In the past, various pattern clustering techniques including expert systems (ES) [1], fuzzy clustering [2], and neural networks (NN) [3] have been extensively used in pattern recognition. Combinations of personal computers (PC), expert systems, and fuzzy systems show the possibilities of automating recognition. However, it is hard to use these rule-based methods to acquire pictorial knowledge, and it is hard to maintain the database of decision rules. The main advantage of an MNN over other classifiers is that it can directly acquire experience from the training data and overcome some of the shortcomings of the expert system. However, the training data must be sufficient and compatible to ensure proper training; its convergence of learning is influenced by the network topology and values of learning parameters. A further limitation of the MNN approach is the inability to produce linguistic output, because it is difficult to understand the content of network memory.

To overcome the limitations of the ES and MNN mentioned above, a new recognition method based on the GA and extension theory is presented for fault diagnosis of car engine in this paper. The concept of extension theory was first proposed by Cai to solve contradictions and incompatibility problems in 1983 [4]. Extension theory consists of two parts, matter-element model and extended set theory. Extension theory is now used in the research field of artificial intelli- 
gence $(\mathrm{AI})$ and its relevant sciences $[5,6]$. With the combination of extension theory and management science, cybernetics, information science, and computer science, extensionengineering methods have been applied to some engineering fields. The drawback of the extension method is that it needs to adjust the weight and the matter-element model by using the experienced rules for enhancing the accuracy. Therefore, this paper will propose using the GA to adjust the matterelement model of the extension method and to achieve the optimal solution to the diagnostic problem. The proposed diagnostic method has been tested on a practical car engine and has also been compared to other traditional classified methods. The results of the experiment show that the GAbased extension recognition method has high accuracy and is much more suitable as a practical solution to the diagnosis problem [7].

\section{Summary of Extension Theory}

Extension theory was first introduced in 1983 by a Chinese scholar, Cai W. There are two main points in extension theory that are matter-element model and extension set $[8,9]$. The hard core of extension theory is two theoretical pillars that include matter-element theory and extension set theory. The former studies matter-elements and their transformations; it can be easy to represent the nature of a matter. The latter is the quantitative tool of extension theory; it can represent the correlation degree of two matter-elements in the designed correlation functions. The combination of these two pillars with other science generates the respective knowledge, which is the soft part of extension theory. Extension theory makes it possible to develop formalized descriptions for activities of creative thinking, such as knowledge innovation, new product designing, and strategy generation.

2.1. Matter-Element Theory. In extension theory, a matterelement uses an ordered triad as the basic element for describing things as follows:

$$
R=(N, c, v),
$$

where $N$ represents the matter and $c$ the characteristics; $v$ is N's measure of the characteristics $c$, where $v$ can be a value or an interval. If we assume that $R=(N, C, V)$ is a multidimensional matter-element, $C=\left[c_{1}, c_{2}, \ldots, c_{n}\right]$ is a characteristic vector, and $v=\left[v_{1}, v_{2}, \ldots, v_{n}\right]$ is a value vector of $C$, then a multidimensional matter-element is defined as follows:

$$
R=(N, C, V)=\left[\begin{array}{c}
R_{1} \\
R_{2} \\
\vdots \\
R_{n}
\end{array}\right]=\left[\begin{array}{ccc}
N, & c_{1}, & v_{1} \\
& c_{2}, & v_{2} \\
& \vdots & \vdots \\
& c_{n}, & v_{n}
\end{array}\right]
$$

where $R_{i}=\left(N, c_{i}, v_{i}\right)(i=1,2, \ldots, n)$ is defined as the submatter-element of $R$. For example,

$$
R=\left[\begin{array}{llc}
\text { Wang, } & \text { Height, } & 178 \mathrm{~cm} \\
& \text { Weight, } & 75 \mathrm{~kg}
\end{array}\right] .
$$

This can be used to state that Wang's height is $178 \mathrm{~cm}$, and his weight is $75 \mathrm{~kg}$. A matter has many characteristics, and one characteristic or characteristic-element can be possessed by many matters. Using the matter-element model, we can describe the quality and quantity of a matter, which is a new concept in mathematical territory.

2.2. Summary of Extension Set Theory. Set theory is a mathematical scheme that describes the classification and pattern recognition about an objective. A cantor set describes the definiteness of matters; a fuzzy set describes the fuzziness of matters. The extension set extends the fuzzy set from $[0,1]$ to $(-\infty, \infty)[10]$. As a result, it allows us to define a set that includes any data in the domain. The extension set is composed of two definitions.

Definition 1. Let $U$ be a space of objects and $x$ a generic element of $U$; then an extension set $\widetilde{E}$ in $U$ is defined as a set of ordered pairs as follows:

$$
\widetilde{E}=\{(x, y) \mid x \in U, y=K(x) \in(-\infty, \infty)\},
$$

where $y=K(x)$ is called the correlation function for the extension set $\widetilde{E}$. $K(x)$ maps each element of $U$ to a membership grade between $-\infty$ and $\infty$. An extension set in $U$ can be denoted by

$$
\widetilde{E}=E^{+} \cup Z_{0} \cup E^{-}
$$

where

$$
\begin{aligned}
E^{+} & =\{(x, y) \mid x \in U, y=K(x)>0\} \\
Z_{0} & =\{(x, y) \mid x \in U, y=K(x)=0\} \\
E^{-} & =\{(x, y) \mid x \in U, y=K(x)<0\} .
\end{aligned}
$$

In (6) and (7), $E^{+}, E^{-}$, and $Z_{0}$ are called the positive field, negative field, and zero boundary in $\widetilde{E}$, respectively.

Definition 2. If $X_{0}=\langle a, b\rangle$ and $X=\langle f, g\rangle$ are two intervals in the real number field, and $X_{0} \cap X$, where $X_{0}$ and $X$ are the classical (concerned) and neighborhood domains, respectively, the correlation function in extension theory can be defined as follows:

$$
K(x)= \begin{cases}-\rho\left(x, X_{0}\right) & x \in X_{0} \\ \frac{\rho\left(x, X_{0}\right)}{\rho(x, X)-\rho\left(x, X_{0}\right)} & x \notin X_{0},\end{cases}
$$

where

$$
\begin{aligned}
& \rho\left(x, X_{0}\right)=\left|x-\frac{a+b}{2}\right|-\frac{b-a}{2}, \\
& \rho(x, X)=\left|x-\frac{f+g}{2}\right|-\frac{g-f}{2} .
\end{aligned}
$$

The correlation function can be used to calculate the membership grade between $x$ and $X_{0}$. The extended membership function is shown in Figure 1. When $K(x)<0$, it 
indicates the degree to which $x$ belongs to $X_{0}$. When $K(x)<$ 0 , it describes the degree to which $x$ does not belong to $X_{0}$. When $-1<K(x)<0$, it is called the extension domain, which means that element $x$ still has a chance to become part of the set if conditions change.

2.3. The Basic Theory of Genetic Algorithm. The best-known evolutionary algorithm (EA) is the genetic algorithm (GA), which transposed the notion of evolution in nature to computers and imitates natural evolution and selection [10, 11]. Basically, a GA finds a solution to a problem by maintaining a population of possible solutions according to the "survival of the fittest" principle. The genetic algorithm constitutes a class of search algorithms especially suited to solving complex optimization problems [11]. In addition to parameter optimization, genetic algorithms are also suggested for solving problems in creative design, such as combining components in a novel creative way. In general, the major advantage of using a GA is that the optimal solution is obtained globally [12]. A genetic algorithm generally includes the following five parts.

(1) Gene Coding. It combines all genes into a chromosome sequence of 0 and 1 .

(2) Fitness Function. It describes the capability of a certain individual gene to reproduce and is usually equal to the proportion of the individual's genes in all genes of the next generation.

(3) Selection Mechanism. It is the intentional manipulation by chromosome of the fitness of individuals in a population to produce a desired evolutionary response.

(4) Crossover. It is a process in which chromosomes exchange genes through the breakage and reunion of two chromosomes.

(5) Mutation. It is a change in a gene resulting in new or rearranged hereditary determinants. Mutations are rare, random events in which the base sequence of the gene is changed.

\section{The GA-Based Extension Recognition Method}

In this paper, the proposed recognized method involves a combination of the genetic algorithm (GA) and extension theory. Extension theory provides a means for distance measurement in the classification process. A genetic algorithm has the ability to search for an optimal solution within a wide space. The proposed GA-based extension recognition method is a kind of supervised learning that finds the best classical domain with better accuracy. This section will present a mathematical description of the proposed recognized method. We need to define several variables before using the algorithm.

3.1. The Training Stage. The chromosomes propagate the next generation of chromosomes to combine the matter-

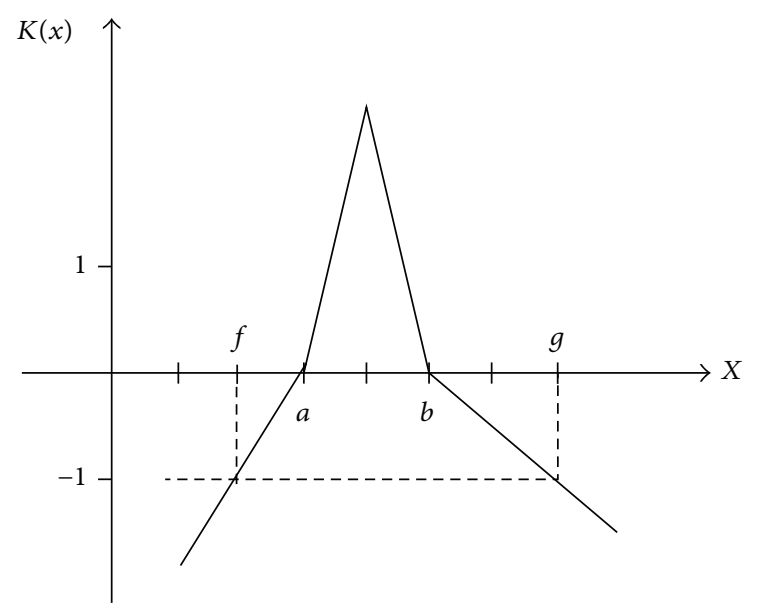

FIgURE 1: The extended membership function.

element models in the proposed method. Setting patterns = $\left\{p_{1}, p_{2}, \ldots, p_{n}\right\}$ with $i$ th as follows: $p_{i j}=\left\{c_{1}, c_{2}, \ldots, c_{k}\right\}$. In the patterns, $i$ is the total number of genes and $j$ is the type of pattern. Using the proposed method can be simply described as follows.

Step 1. Set the epoch, the crossover rate $C_{r}$, the mutation rate $m_{u}$, the tolerance of error rate $E_{r}$, and the chromosome rate $R_{a}$.

Step 2. Find the genes with lower limit and upper limit value:

$$
\begin{aligned}
& v_{a}^{j}=\min \left(c_{k n}^{j}\right) \\
& v_{b}^{j}=\min \left(c_{k n}^{j}\right) \\
& v^{j}=\left\langle v_{a}^{j}, v_{b}^{j}\right\rangle,
\end{aligned}
$$

where $k$ is the number of characteristics, $v_{a}$ is the upper limit, and $v_{b}$ is the lower limit.

Step 3. Produce new genes with lower limit and upper limit values with the chromosome rate. The chromosome rate is produced by a random generator. Consider

$$
\begin{aligned}
& v_{a}^{j}-R_{a} \leq G_{L}^{j} \leq v_{a}^{j}+R_{a} \\
& v_{b}^{j}-R_{a} \leq G_{L}^{j} \leq v_{b}^{j}+R_{a} .
\end{aligned}
$$

Step 4. The genes make up the chromosome. Consider

$$
\text { chrom }=\left\{G_{L}^{11}, G_{L}^{11}, G_{L}^{12}, G_{L}^{12}, \ldots, G_{L}^{j k}\right\} .
$$

The number of genes in a chromosome is calculated by function $2 * k * j$.

Step 5. Build the matter-element model from the genes. Consider

$$
R_{j}=\left[\begin{array}{ccc}
N, & c_{1}, & \left\langle G_{L}^{1}, G_{U}^{1}\right\rangle \\
c_{2}, & \left\langle G_{L}^{2}, G_{U}^{2}\right\rangle \\
\vdots & \vdots \\
c_{n}, & \left\langle G_{L}^{k}, G_{U}^{k}\right\rangle
\end{array}\right] \quad j=1,2, \ldots, m .
$$


Step 6. Input the training of data that is the value of gene. Consider

$$
x^{j}=\left\{c_{1}, c_{2}, \ldots, c_{k}\right\} .
$$

Step 7. Calculate the correlation function. Consider

$$
\begin{gathered}
z^{k}=\left(G_{L}^{k}+G_{U}^{k}\right) \\
K_{n k}=\sum_{i=1}^{n}\left[\frac{\left|x_{n k}^{j}-z_{j k}\right|-\left(G_{U}^{j k}-G_{L}^{j k}\right) / 2}{\left|\left(G_{U}^{j k}-G_{L}^{j k}\right) / 2\right|}+1\right] .
\end{gathered}
$$

Step 8. Normalize the value of the correlation function for the matter-element model to be between 1 and -1 .

Step 9. Input the next training of data to repeat Steps 6 through 8.

Step 10. Input the next matter-element model and repeat Steps 5 through 9.

Step 11. Calculate the fitness function. Consider:

$$
\text { Fitness }=\frac{N_{r}}{N_{a}},
$$

where $N_{r}$ is the right amount and $N_{a}$ is the total amount.

Step 12. The selection of parental chromosomes is put into the mating pool, and the genes implement a cross over mechanism.

Step 13. Let the next generation of chromosomes replace the chromosomes and implement the mutation mechanism.

Step 14. Calculate the correct rate. Consider

$$
E_{r}=(1-\text { Fitness }) \times 100 \% .
$$

Step 15. Continue until training is finished. If the training process is not finished, go to Step 3.

\subsection{The Recognizing Stage}

Step 1. Build the matter-element model by using an optimization solution. Consider

$$
R_{j}=\left[\begin{array}{ccc}
N, & c_{1}, & \left\langle G_{L}^{1}, G_{U}^{1}\right\rangle \\
c_{2}, & \left\langle G_{L}^{2}, G_{U}^{2}\right\rangle \\
\vdots & \vdots \\
c_{n}, & \left\langle G_{L}^{k}, G_{U}^{k}\right\rangle
\end{array}\right] \quad j=1,2, \ldots, m .
$$

Step 2. Input the data that is recognized. Consider

$$
x^{j}=\left\{c_{1}, c_{2}, \ldots, c_{k}\right\} .
$$

Step 3. Calculate the correlation function. Consider

$$
\begin{gathered}
z^{k}=\frac{\left(G_{L}^{k}+G_{U}^{k}\right)}{2} \\
K_{n k}=\sum_{i=1}^{n}\left[\frac{\left|x_{n k}^{j}-z_{j k}\right|-\left(G_{U}^{j k}-G_{L}^{j k}\right) / 2}{\left|\left(G_{U}^{j k}-G_{L}^{j k}\right) / 2\right|}+1\right] .
\end{gathered}
$$

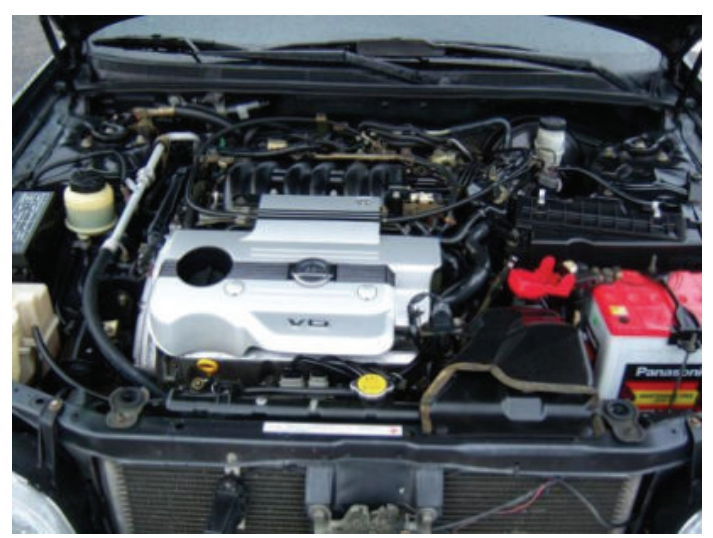

Figure 2: The engine of Nissan Cefiro 2.0.

Step 4. Find $\min \left(K_{n k}\right)$. If $K_{n t}$ is bigger than $k$, then the data does not belong to any group set.

Step 5. Continue until recognizing is finished. If it is not finished, go to Step 2.

\section{Fault Diagnosis of Car Engine}

The tested object of this research is the engine of the Nissan Cefiro 2.0. As shown in Figure 2, the engine temperature is working between 80 and $95^{\circ} \mathrm{C}$, and the base configuration of the engine has about $1.0 \mathrm{~mm}$ spark-plug gap. At the time of the experiment, the car was in the parked gear when the engine was in either a normal condition or the fault tests condition.

4.1. The Tested Configuration. The main specifications of the engine are shown in Table 1. The back pressure was received by a digital storage oscilloscope by using a pressure transmitter; the exhaust temperature was received by a temperature sensor. The exhaust component was received by an exhaust gas analyzer. The experimental structure is shown in Figure 3. The engine signals were all delivered to the diagnosis system by the sensors, and the detailed records of signals were easily designed by LabView 8.5 software [13]. Typical screenshots of the fault diagnostic software are shown in Figures 4 and 5. Here, the fault types are divided into 16 types (including no fault), and there are 8 characteristics for the input data. The components of engine exhaust include $\mathrm{HC}$ (ppm), CO (\%), and $\mathrm{CO}_{2}(\%)$, and this study separately installed the temperature sensor in $T 1, T 2, T 3$, and $T 4$ so that we could promptly monitor the temperature for every exhaust position in order to speculate on engine faults. The exhaust pressures relative to the multiple frequencies of the engine's rotational speed are shown in Table 2 . The processed data was sent to the next stage for fault diagnosis.

4.2. Testing Results and Discussion. In this paper, 208 sets of tested data were used according to [14] to test the practicability of the proposed method. In the training stage, there were 160 sets of training data, as shown in Table 3 . The other data (48 sets) was used to test patterns. The input data of a fault diagnosis system will unavoidably contain some uncertainties 


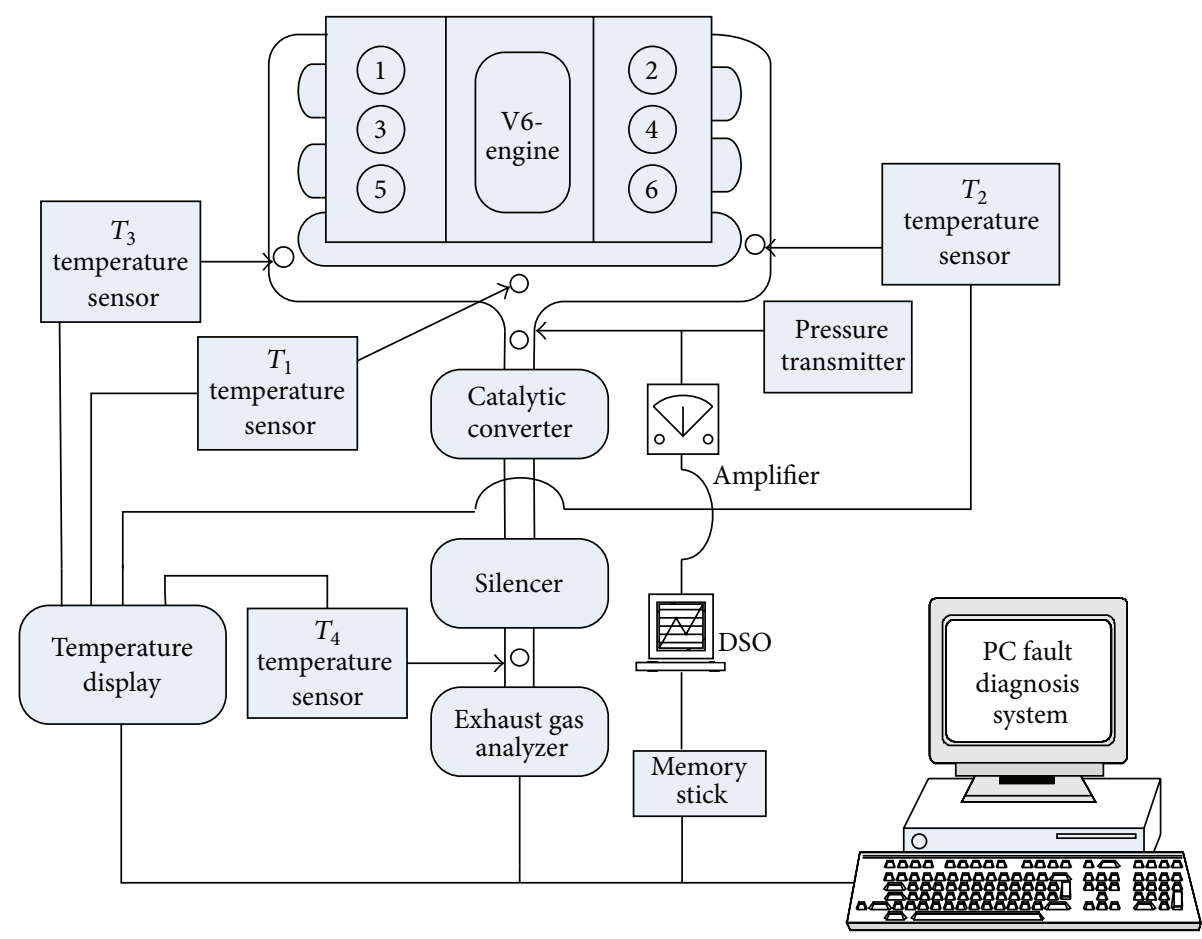

Figure 3: The experimental structure.

TABLE 1: The main specifications of the car engine.

\begin{tabular}{|c|c|c|c|c|c|c|c|}
\hline Engine from & Fuel supply style & $\begin{array}{l}\text { The cylinder } \\
\text { arranging }\end{array}$ & Valve train & Displacement & $\begin{array}{l}\text { Compression } \\
\text { ratio }\end{array}$ & $\begin{array}{l}\text { Maximum horse } \\
\text { power }\end{array}$ & $\begin{array}{l}\text { Maximum } \\
\text { torque }\end{array}$ \\
\hline $\begin{array}{l}\text { Six-cylinder } \\
\text { four-stroke petrol } \\
\text { engine }\end{array}$ & $\begin{array}{l}\text { Electronic ignition } \\
\text { and engine-control } \\
\text { computer }\end{array}$ & V6 & DOHC $24 \mathrm{~V}$ & $5 \mathrm{cc}$ & $9.5: 1$ & $150 \mathrm{ps} / 6400 \mathrm{rpm}$ & $\begin{array}{c}19.3 \mathrm{~kg}- \\
\mathrm{m} / 4000 \mathrm{rpm}\end{array}$ \\
\hline
\end{tabular}

TABLE 2: Fault types relative to the multiple frequency of the engine rotational speed.

\begin{tabular}{|c|c|c|}
\hline Items & Fault types & $\begin{array}{c}\text { Characteristic } \\
\text { frequency } 9.5 \text { th } \sim 12 \text { th } \\
\text { multiple frequencies }\end{array}$ \\
\hline 1 & No fault & Nothing \\
\hline 2 & Spark plug is too large to $2.0 \mathrm{~mm}$ & Nothing \\
\hline 3 & Spark plug is too small to $0.2 \mathrm{~mm}$ & 12 \\
\hline 4 & No fuel injection in the 1st cylinder & $9.5,10.5,12$ \\
\hline 5 & No fuel injection in the 2 nd cylinder & $9.5,12$ \\
\hline 6 & No fuel injection in the 3rd cylinder & $9.5,10.5,12$ \\
\hline 7 & No fuel injection in the 4 th cylinder & $9.5,12$ \\
\hline 8 & No fuel injection in the 5 th cylinder & $9.5,10.5,12$ \\
\hline 9 & No fuel injection in the 6th cylinder & $9.5,12$ \\
\hline 10 & No ignition in the 6th cylinder & $9.5,10.5,12$ \\
\hline 11 & No ignition in the 5 th cylinder & $9.5,12$ \\
\hline 12 & No ignition in the 4 th cylinder & $9.5,10.5,12$ \\
\hline 13 & No ignition in the 3 rd cylinder & $9.5,12$ \\
\hline 14 & No ignition in the 2 nd cylinder & $9.5,10.5,12$ \\
\hline 15 & No ignition in the 1st cylinder & $9.5,12$ \\
\hline 16 & Oxygen sensor malfunction & 12 \\
\hline
\end{tabular}


TABLE 3: The engine fault data and fault types (partial samples).

\begin{tabular}{|c|c|c|c|c|c|c|c|c|c|c|}
\hline \multirow{2}{*}{ Number } & \multicolumn{4}{|c|}{ Temperature } & \multicolumn{3}{|c|}{ Exhaust } & \multirow{2}{*}{$\begin{array}{l}10.5 \text { multiple } \\
\text { frequencies }\end{array}$} & \multirow{2}{*}{ Fault number } & \multirow{2}{*}{ Fault types } \\
\hline & $T_{1}$ & $T_{2}$ & $T_{3}$ & $T_{4}$ & CO (\%) & $\mathrm{HC}(\mathrm{ppm})$ & $\mathrm{CO}_{2}(\%)$ & & & \\
\hline 11 & 207 & 288 & 213 & 82 & 0.11 & 40 & 14.21 & 2 & 1 & Normal \\
\hline 66 & 313 & 258 & 240 & 152 & 0.03 & 0 & 12.89 & 2 & 5 & $\begin{array}{l}\text { The second cylinder not fuel } \\
\text { injection }\end{array}$ \\
\hline 89 & 276 & 221 & 245 & 84 & 0.18 & 50 & 12.82 & 2 & 7 & $\begin{array}{l}\text { The fourth cylinder not fuel } \\
\text { injection }\end{array}$ \\
\hline 102 & 305 & 279 & 233 & 95 & 2.11 & 100 & 12 & 1 & 8 & $\begin{array}{l}\text { The fifth cylinder not fuel } \\
\text { injection }\end{array}$ \\
\hline 127 & 392 & 263 & 246 & 116 & 2.9 & 100 & 13.53 & 2 & 10 & $\begin{array}{l}\text { The sixth cylinder not ignition } \\
\text { cylinder }\end{array}$ \\
\hline 152 & 372 & 237 & 254 & 115 & 2.89 & 180 & 13.47 & 2 & 12 & $\begin{array}{l}\text { The fourth cylinder not ignition } \\
\text { cylinder }\end{array}$ \\
\hline 175 & 364 & 257 & 237 & 111 & 2.94 & 370 & 13.12 & 2 & 14 & $\begin{array}{l}\text { The second cylinder not ignition } \\
\text { cylinder }\end{array}$ \\
\hline 195 & 260 & 301 & 233 & 131 & 0.06 & 50 & 14.49 & 2 & 16 & Oxygen sensor malfunction \\
\hline
\end{tabular}

TABLE 4: Diagnosis performances of methods compared.

\begin{tabular}{lcc}
\hline Method & Training time & Accuracy rate (\%) \\
\hline Proposed method & 1000 & $98 \%$ \\
K-means method & N/A & $85 \%$ \\
MNN-I (8-8-16) & 1000 & $62 \%$ \\
MNN-II (8-10-16) & 1000 & $80 \%$ \\
MNN-III (8-15-16) & 1000 & $95 \%$ \\
\hline
\end{tabular}

TABLE 5: Diagnosis performances of proposed method.

\begin{tabular}{lc}
\hline Noise percentage (\%) & Accuracy rate (\%) \\
\hline $\pm 0 \%$ & $98 \%$ \\
$\pm 5 \%$ & $95 \%$ \\
$\pm 10 \%$ & $87 \%$ \\
$\pm 15 \%$ & $77 \%$ \\
$\pm 20 \%$ & $65 \%$ \\
\hline
\end{tabular}

and noise. The sources of error include environmental noise, transducers, and human mistakes, all of which can lead to data uncertainties. To take the noise and uncertainties into account, 1,800 sets of testing data were created by adding $\pm 5 \%$ to $\pm 15 \%$ of random, uniformly distributed error to the training data in order to appraise the fault-tolerant abilities of the proposed method. To take noise and uncertainties into account, 48 sets of testing data were created by adding $\pm 5 \%$ to $\pm 20 \%$ of random, uniformly distributed errors to the training data, in order to appraise the fault-tolerant abilities of the proposed method. The reason for this is that the input data of an engine system will contain some noise and uncertainties. Table 4 shows the recognition results of different methods. When using the multilayer neural network (MNN) and kmeans-based methods to diagnose the faults of the engine, the maximum accuracy was $95 \%$ for the MNN-based method and $85 \%$ in the k-means-based method. The accuracy of the proposed diagnostic method is $98 \%$, which is quite high and better than the other methods.

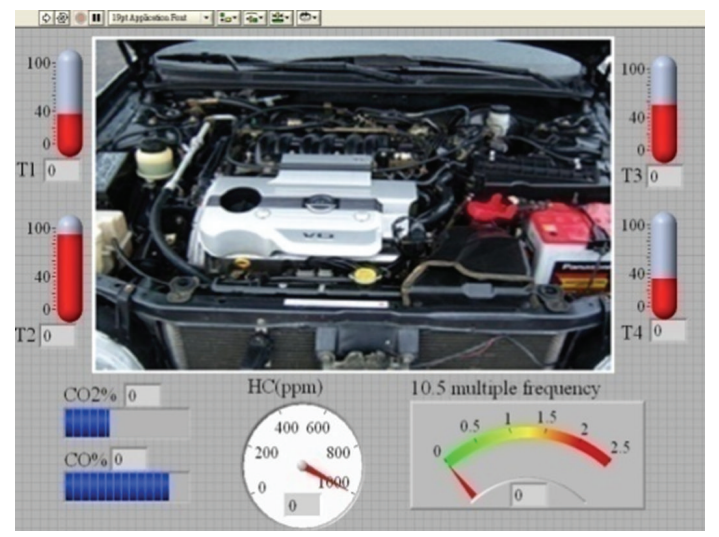

FIgURE 4: The LabView recording of the fault diagnosis system.

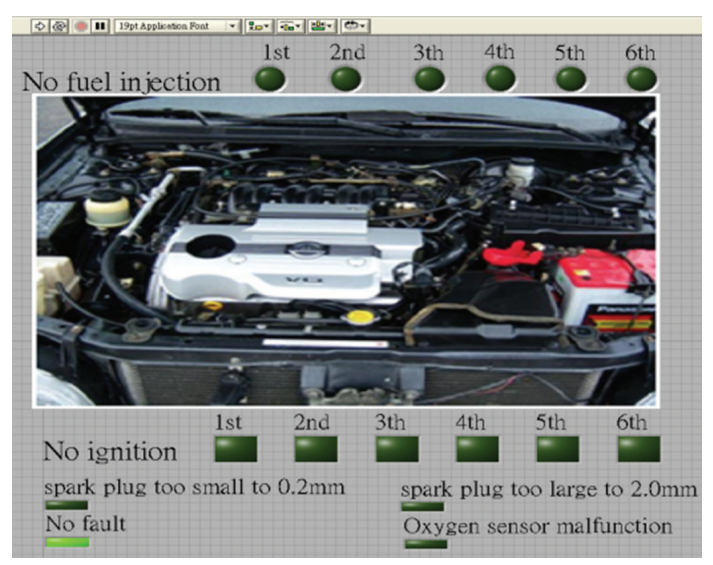

FIGURE 5: The fault diagnosis system.

The test results using different numbers of added errors are shown in Table 5. Usually, the error-containing data degrades the recognition capabilities in proportion to the number of errors added. This table shows that these methods all bear remarkable tolerance to the errors contained in the 
data. The proposed method shows good tolerance to added errors and has high accuracy rate of $65 \%$ in the extreme case where the errors were $\pm 20 \%$.

\section{Conclusions}

This paper presents a novel fault diagnosis method for car engines based on GA and extension theory. The calculation of the proposed recognized method is fast and very simple. It can be easily implemented by PC software. When a diagnosed data is input into the proposed diagnosis system, the proposed recognized method will output the possibility of all fault types. It provides useful information to engine fault diagnosis and maintenance. Test results show that the proposed method does not only diagnose the main fault types but can also detect useful information about future trends and multifault analysis. Moreover, the proposed method has a significantly higher degree of diagnosis accuracy than current methods and shows good tolerance to added errors.

\section{Conflict of Interests}

The authors declare that there is no conflict of interests regarding the publication of this paper.

\section{References}

[1] B. Das, "Fuzzy logic-based fault-type identification in unbalanced radial power distribution system," IEEE Transactions on Power Delivery, vol. 21, no. 1, pp. 278-285, 2006.

[2] B. Kerezsi and I. Howard, "Vibration fault detection of large turbogenerators using neural networks," in Proceedings of the IEEE International Conference on Neural Networks, vol. 1, pp. 121-126, December 1995.

[3] M. B. I. Reaz, F. Choong, M. S. Sulaiman, F. Mohd-Yasin, and M. Kamada, "Expert system for power quality disturbance classifier," IEEE Transactions on Power Delivery, vol. 22, no. 3, pp. 1979-1988, 2007.

[4] S.-F. Hwang and R.-S. He, "A hybrid real-parameter genetic algorithm for function optimization," Advanced Engineering Informatics, vol. 20, no. 1, pp. 7-21, 2006.

[5] M. H. Wang and P. Y. Chen, "Using extension theory to design a low-cost and high-accurate personal recognition system," International Journal of Distributed Sensor Networks, vol. 2013, Article ID 952568, 12 pages, 2013.

[6] F. Yang and C. Zhang, "Research of an integration model combining rough set with extension theory for fault diagnosis," in Proceedings of the 2nd International Conference on Mechanic Automation and Control Engineering (MACE '11), pp. 5131-5134, July 2011.

[7] X. Yuan, "A new extension theory-based production operation method in industrial process," Chinese Journal of Chemical Engineering, vol. 21, no. 1, pp. 44-54, 2013.

[8] Z. Y. Lei and W. Chen, "Safety evaluation of fire protection system of high-rise building based on matter-element extension method," Journal of Yangtze University, vol. 6, no. 2, 2009.

[9] G. Renner and A. Ekárt, "Genetic algorithms in computer aided design," Computer Aided Design, vol. 35, no. 8, pp. 709-726, 2003.
[10] J. C. Tovar and W. Yu, "Fuzzy neural modeling via clustering and support vector machines," in Proceedings of the 16th IEEE International Conference on Control Applications (CCA '07), pp. 2429, October 2007.

[11] S. J. Aguilar-Ruiz, R. Giráldez, and J. C. Riquelme, "Natural encoding for evolutionary supervised learning," IEEE Transactions on Evolutionary Computation, vol. 11, no. 4, pp. 466-479, 2007.

[12] W. Cai, "The extension set and incompatibility problem," Journal of Scientific Exploration, vol. 1, no. 1, pp. 81-93, 1983.

[13] W. Cai, "Extension theory and its application," Journal of Scientific Exploration, vol. 44, no. 7, pp. 673-682, 1999.

[14] Y. Y. Chen, An artificial neural network model for the diagnosis of automotive engine [thesis], National Chung Hsing University, 2006. 


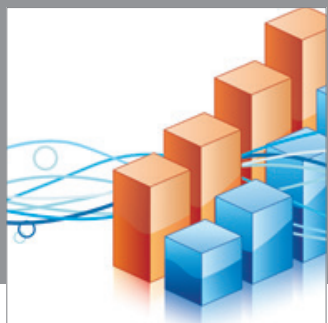

Advances in

Operations Research

mansans

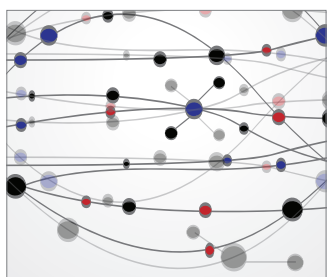

The Scientific World Journal
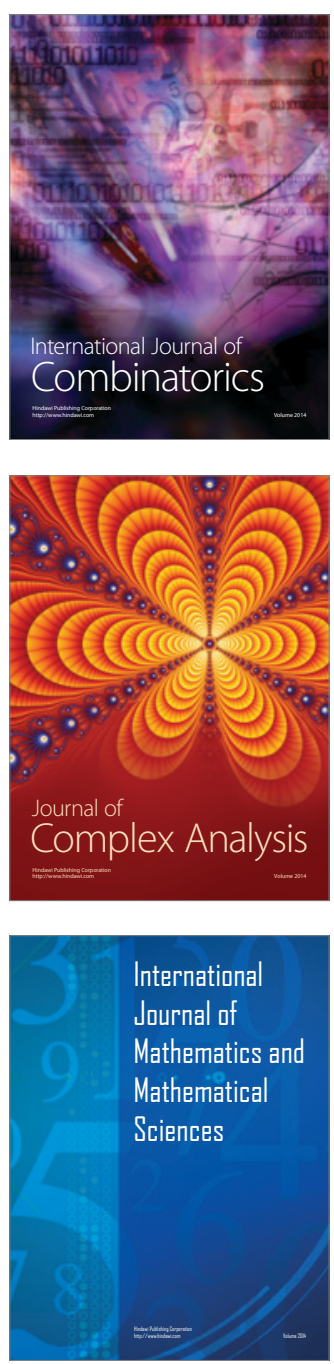
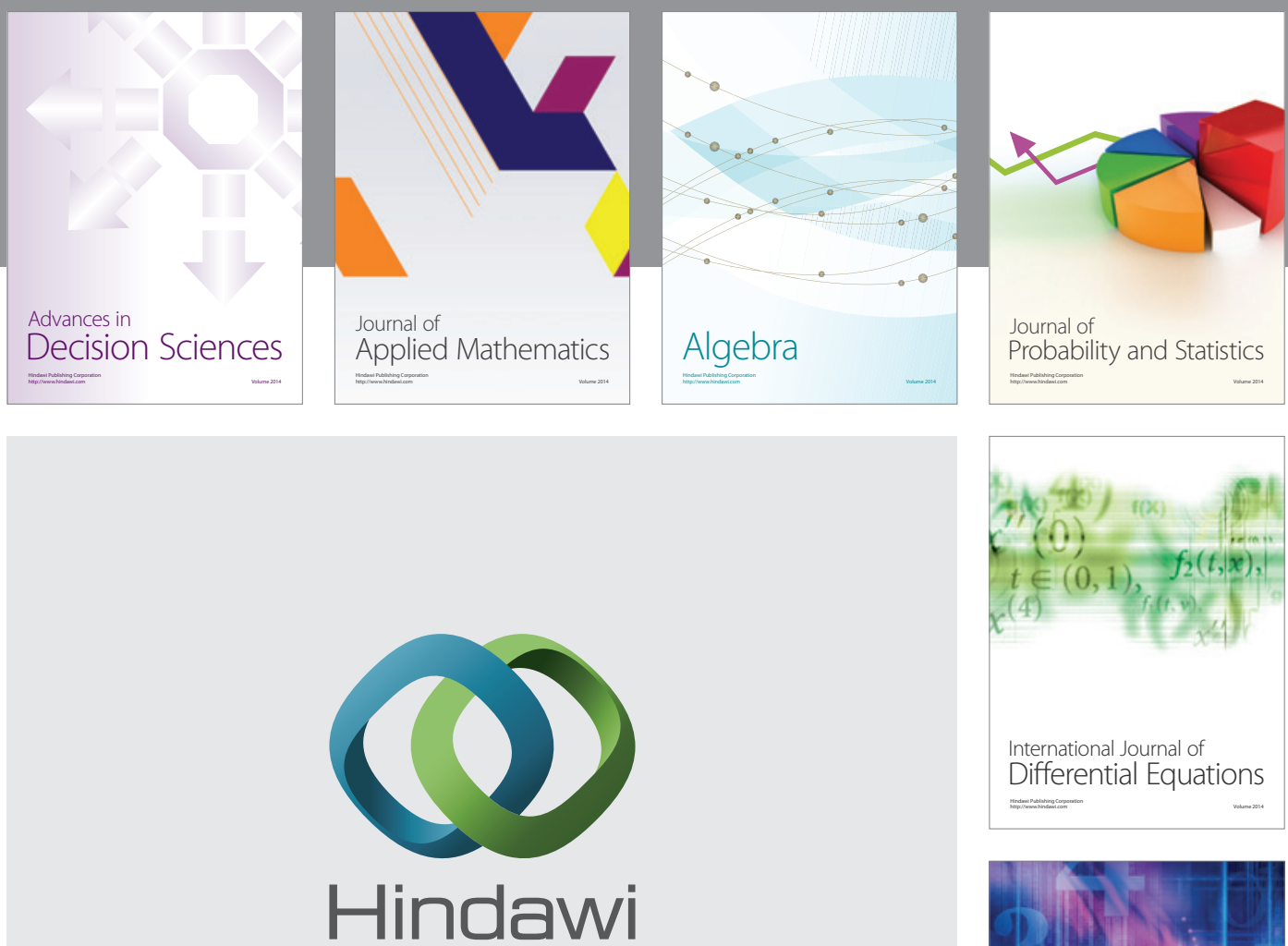

Submit your manuscripts at http://www.hindawi.com
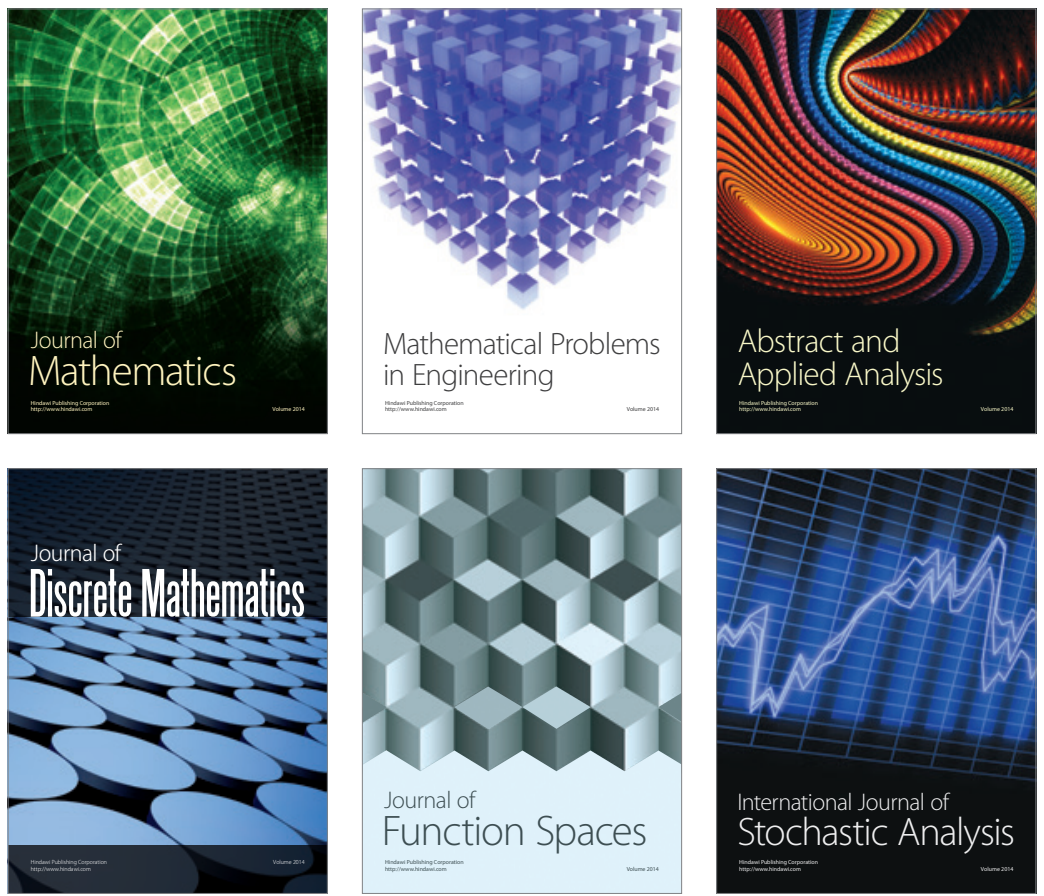

Journal of

Function Spaces

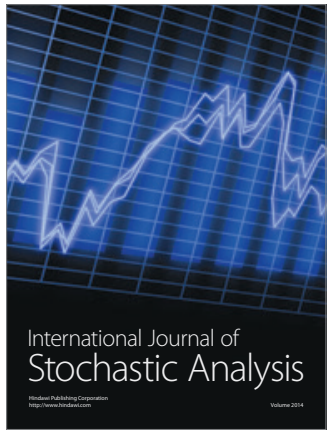

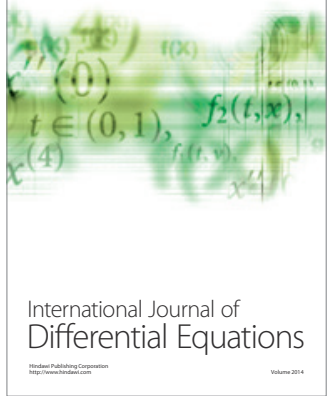
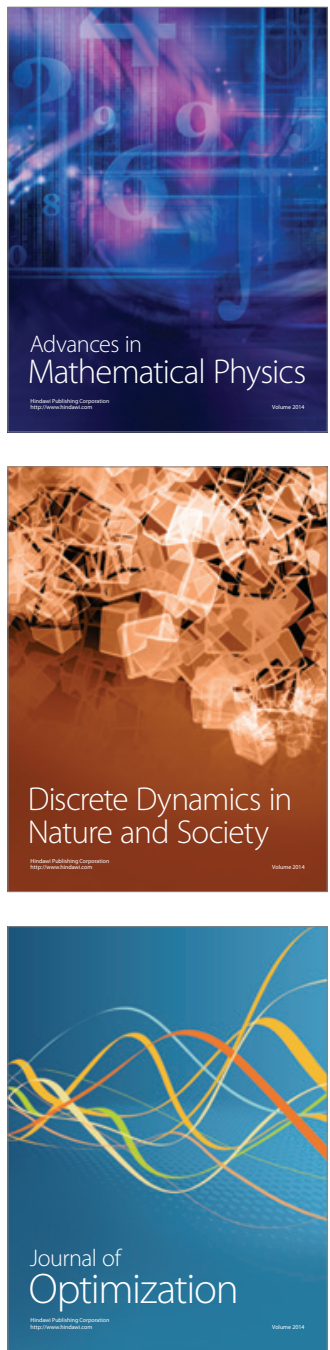